\title{
La deserción estudiantil en la Universidad de Los Andes (Venezuela)
}

\section{Student desertion at the University of Los Andes (Venezuela)}

\author{
José Matías Albarrán Peña \\ Universidad de Los Andes, Mérida, Venezuela.
}

\section{Resumen}

Objetivo: Se presenta un análisis que permite aproximar al lector a la deserción estudiantil en la Universidad de Los Andes (ULA-Venezuela), con el objeto de interpretar los factores que podrían estar generando la ausencia de los estudiantes de las aulas de clases. Método: Se consultó google académico, Dialnet y Latindex con las palabras claves: deserción universitaria, abandono estudiantil, universidades venezolanas. Es importante indicar que no se contaron con datos oficiales que midieran el fenómeno, por tanto la información fue extraída de estimaciones de organizaciones no gubernamentales o diarios en línea. Resultados: Los hallazgos revelan que un $65 \%$ de los estudiantes podrían haber desertado, debido a la falta de oportunidades laborales futuras, aumento de sus gastos personales y académicos, interrupción de las labores académicas por continuas protestas sociales, carencia de recursos económicos, baja formación escolar secundaria y desmotivación, principalmente. Discusión: La deserción en la ULA es un fenómeno creciente que aumenta a medida la crisis económica del país se agrava. Conclusión: Se debe brindar apoyo motivacional y académico al estudiante para que permanezca en las aulas a pesar de las vicisitudes sociales y económicas presentes en el país.

Palabras clave: causas, deserción estudiantil, migración, universidades.

\begin{abstract}
Objective: We present an analysis that allows us to approximate the student dropout at the University of Los Andes (ULA-Venezuela), in order to interpret the factors that could be generating the absence of students from classrooms. Method: Google academic, Dialnet and Latindex were consulted with the key words: university desertion, student abandonment, Venezuelan universities. It is important to indicate that there were no official data to measure the phenomenon, so the information was extracted from estimates of non-governmental organizations or online journals. Results: The findings reveal that $65 \%$ of students could have dropped out, due to lack of future job opportunities, increase of their personal and academic expenses, interruption of academic work due to continuous social protests, lack of economic resources, low training secondary school and demotivation, mainly. Discussion: The desertion in the ULA is a growing phenomenon that increases as the economic crisis of the country worsens. Conclusion: Motivational and academic support should be provided to the student so that he remains in the classrooms despite the social and economic vicissitudes present in the country.
\end{abstract}

Keywords: causes, student desertion, migration, universities.
ISSN: 0124-2121

E-ISSN: 2665-2420

Open Access:

Editor:

Patricia Martínez Barrios Universidad Simón Bolívar

Correspondencia:

José Alabrrán josematias1@hotmail.c

Recibido: $14-11-17$ Aceptado: 25-04-18 Publicado: $12-12-18$ 


\section{Introducción}

Venezuela, actualmente, se encuentra sumida en una situación política y económica difícil, debido a la concurrencia de determinados problemas sociales que inciden en el bienestar individual y colectivo de la población. El aumento de los niveles de pobreza, como consecuencia del incremento de la tasa de inflación y la falta de divisas suficientes por la reducción de los precios del petróleo, ha ocasionado un proceso de migración atípico en la población venezolana, especialmente, en los individuos más jóvenes, quienes agobiados por la falta de oportunidades laborales y la insatisfacción de sus necesidades básicas, deciden salir del país. Muchos son los destinos que toman los migrantes y van desde naciones suramericanas hasta europeas, en las cuales les sea posible obtener un empleo que les permita cubrir sus gastos. Sin embargo, dentro de este fenómeno migratorio, profesionales altamente cualificados también emprenden viaje a nuevos horizontes, que les ayude a lograr sus metas y anhelos personales.

La migración de venezolanos parece incrementarse y según cifras aportadas por el Observatorio de la Diáspora Venezolana (2017), 2 millones de personas han salido del país (Para, 2017). Apenas obtienen sus títulos universitarios, muchos profesionales tramitan sus documentos y buscan financiamiento para viajar a rumbos desconocidos, donde puedan trabajar o desempeñarse de manera transitoria en algún oficio que le sirva para subsistir momentáneamente, mientras obtienen un empleo relacionado con sus carreras académicas. Dentro de este contexto, las universidades han comenzado a experimentar, cada vez más, la creciente deserción estudiantil en las aulas de clases. Es muy común observar que las asignaturas, cursos y seminarios que se dictan en las diferentes facultades, no cuenten con la demanda estudiantil necesaria o que menos de la mitad de los inscritos sean quienes terminen el período lectivo.

Esta problemática es un fenómeno muy complejo que ha puesto de manifiesto, en la población estudiantil, la falta de recursos económicos necesarios para la continuación de sus estudios, pues al verse limitados optan por trabajar o emigrar, ausentándose de las instituciones de enseñanza profesional. De acuerdo con López y Beltrán (2012) la deserción se entiende como el abandono de los estudios por causas multifactoriales relacionadas con dificultades individuales o ajenas al individuo que le imposibilitan permanecer en un programa educativo. En el caso venezolano, dentro del abandono de los estudios confluyen diversos aspectos, principalmente, los atinentes a la situación económica de la nación.

La deserción, por lo tanto, se ve sujeta al surgimiento de dificultades socioeconómicas que provocan en el joven universitario una desmotivación y apatía hacia los estudios de pregrado, pues sienten que la culminación de la carrera no corresponderá con la obtención en un corto plazo de una determinada oportunidad laboral. Asimismo, la carencia de dinero para sufragar los gastos de vivienda, alimentación, vestido, calzado, transporte, libros, fotocopiado de textos, adquisición de materiales y equipos para prácticas de laboratorio, entre otros aspectos, genera incertidumbre e incapacidad para cubrir estas 
necesidades, obligando al joven a desincorporarse de sus estudios.

Aunado a lo anterior, el Estado no ofrece alternativas de reclutamiento organizado de posibles profesionales en las distintas áreas del desarrollo del país, puesto que la actual economía se encuentra en su nivel más bajo de crecimiento. Las cifras del Banco Mundial (2017) revelan la contracción del Producto Interno Bruto en más del $12 \%$ en el año 2016, el aumento de la inflación en $741 \%$ hasta febrero de 2017 y un déficit fiscal de $20 \%$. Estos parámetros económicos tienen su correspondencia con el incremento de la crisis y la evidente repercusión social, reflejada en el aumento de los niveles de pobreza a $82 \%$ en los hogares venezolanos (Agencia EFE, 2017).

Ciertamente, un país sumergido en una profunda crisis económica causa malestar en los ciudadanos e influye en el estado emocional en un momento específico. En Venezuela, cursar una carrera universitaria, a pesar de que la Constitución Nacional establece la gratuidad en los estudios de tercer nivel, resulta ser una actividad expuesta a la falta de prosecución. Sobre la base de lo antes mencionado, se presenta un análisis de la deserción estudiantil en la Universidad de Los Andes (ULA), ubicada en el estado Mérida. Es importante aclarar que el asunto de la deserción estudiantil en las principales casas de estudio venezolanas, comienza a ser abordado y, por ende, no se cuenta con mediciones exactas que permitan apreciar la magnitud del fenómeno. No obstante, la indagación en algunas facultades de la institución, constituyen datos para una valoración de las posibles causas que han motivado a contar con menos estudiantes en las aulas de clases.

\section{Planteamiento del Problema}

La deserción estudiantil, como fenómeno que provoca la disminución de las posibilidades de desarrollo de un país, amenaza con convertirse en un patrón habitual que traerá el incremento del nivel de subdesarrollo. Hernández (2017) señala que en la Escuela de Educación de la Universidad Central de Venezuela (UCV) el número de estudiantes no llega a mil, en comparación con años anteriores que tenía el mayor número de universitarios. Por su parte, Franquis (2017) reporta que esta deserción se incrementa en un $50 \%$ en aquellos estudiantes de nuevo ingreso. Similar cifra se reporta para la ULA. De igual modo, Luengo, (2017) indica que en la Universidad del Zulia (LUZ) el porcentaje es de $35 \%$, mientras que en las universidades privadas la deserción es de $30 \%$.

Estos datos se toman con base en el manejo de estadísticas por parte de los profesores de las diferentes asignaturas y suponen el crecimiento del número de alumnos que abandonan las aulas desde el comienzo de los períodos lectivos. Sin embargo, diariamente, las cifras van en aumento y cada vez más los estudiantes se ausentan de las instituciones sin realizar el trámite de retiro correspondiente, lo cual impide medir el fenómeno de manera adecuada, pues al no contar con estadísticas fiables se corre el riesgo de especular e hipotetizar las posibles causas del ausentismo estudiantil.

En cuanto a la ULA, es pertinente señalar que tras las protestas antigubernamentales en los meses de abril a julio de 2017 , el porcentaje de deserción no mostraba cifras tan 
significativas como las que se observan, actualmente. En el inicio del mes de septiembre de ese año, después del receso docente, la cantidad de estudiantes que desertaron se incrementó, paulatinamente. De acuerdo con Lobo (2017) durante los años 2005 al 2015, el número de estudiantes que se retiraron de las aulas fue de 3600 , representando una cantidad elevada para la institución. González (2016) señala que en los años 2005-2014 han desertado 36821 estudiantes y establece que, anualmente, se retiraron 3 mil jóvenes universitarios.

Resulta preocupante observar el incremento desmedido del ausentismo estudiantil en las distintas facultades de esta universidad. Es frecuente contemplar como en las distintas asignaturas la asistencia se mantiene por debajo del $50 \%$ de estudiantes inscritos. En muchos casos, aquellas carreras relacionadas con la formación de educadores han dejado de ser interesantes para los alumnos, dadas las pocas posibilidades de obtención de un empleo inmediato en el sector docente y los bajos sueldos que devengan los educadores.

En otro orden de ideas, aquellas carreras vinculadas a las ciencias sociales y económicas también reportan una disminución en su matrícula al igual que las vinculadas con la ingeniería y el medio ambiente. Es oportuno indicar que la ULA, está recopilando los datos necesarios para presentar cifras acordes con la realidad que reflejen el porcentaje de deserción en sus aulas. No obstante, la situación va a reflejar un crecimiento de la cantidad de alumnos que abandonan sus estudios por diversas razones, vinculadas directamente, con el incremento de la crisis económica de la nación.

\section{Fundamentación Teórica}

\section{Deserción estudiantil}

La deserción, entendida como el abandono de los estudios, ha sido abordada como un fenómeno conductual del individuo que se mantiene presente en los distintos niveles de la educación. Desde los niveles de primaria hasta el universitario, ha existido un comportamiento irregular en los sujetos que aprenden. En ciertas ocasiones, las causas del abandono radican en las dificultades personales y en la falta de políticas de motivación por parte de las instituciones educativas que impacta en la permanencia de los estudiantes en un determinado sistema. A continuación se abordan algunos aspectos teóricos que permiten la comprensión de la deserción estudiantil.

Blanco (2013) señala que:

La deserción estudiantil constituye, por su magnitud, un problema importante en los sistemas educativos en toda Latinoamérica. Las altas tasas de abandono de los estudios que se producen en todos los niveles educativos afectan negativamente los procesos económicos, sociales y culturales en el desarrollo de Venezuela. (p. 290).

Como se puede apreciar, el autor expone la regularidad con que se presenta este fenómeno en la educación, que es propio de las aulas de clases de los distintos niveles educativos y señala que esta problemática tiende a afectar el crecimiento de una nación, 
dado que los recursos que se invierten en la permanencia de un individuo en un ambiente de aprendizaje, son desperdiciados y no existe retribución al Estado cuando un estudiante se retira del sistema educativo.

González, Uribe y González (2005) al referirse a la deserción estudiantil universitaria señalan que:

Se puede definir como el proceso de abandono, voluntario o forzoso de la carrera en la que se matricula un estudiante, por la influencia positiva o negativa de circunstancias internas o externas a él o ella. (...) en forma más operativa [es] la cantidad de estudiantes que abandona el sistema de educación superior entre uno y otro período académico (semestre o año). (p.15).

En la anterior definición se expresa, en términos cuantitativos y cualitativos, el significado de la deserción universitaria como el retiro forzoso o libre de un estudiante del sistema educativo superior, imposibilitándose la prosecución de sus estudios por motivos vinculados a su entorno familiar y personal o por factores vinculados con el proceso de formación.

Castaño, Gallón, Gómez y Vázquez (2004) diferencian los tipos de deserción universitaria de la siguiente manera:

Con respecto al tiempo y al espacio. La deserción con respecto al tiempo se clasifica a su vez en: a) deserción precoz: individuo que habiendo sido aceptado por la universidad no se matricula, b) deserción temprana: individuo que abandona sus estudios en los cuatro primeros semestres de la carrera, c) deserción tardía: individuo que abandona los estudios en los últimos seis semestres, es decir, a partir del quinto semestre en adelante. (p.45).

Esta clasificación se relaciona con el momento en cual el estudiante deserta de la institución, influenciado por diversos factores que afectan la persistencia y continuidad en el estudio de una determinada carrera, presentándose con mayor predominancia el abandono en los últimos semestres, lo que implica la carencia de mecanismos de prosecución de parte de las universidades que motiven hacia la obtención del título académico.

El Centro Interuniversitario de Desarrollo (2006) expone que las causas de la deserción en el ámbito universitario pueden provenir de: condiciones socioeconómicas del estudiante, falta de subsidios académicos, excesiva formación teórica en detrimento de una formación adaptada a un campo laboral específico, ausencia de orientación por parte de los docentes, escasa preparación del docente para interpretar las necesidades e intereses de los alumnos, uso continuado de pruebas o exámenes, incoherencia entre las expectativas estudiantiles y los programas de estudio, falta de adaptación al sistema universitario, entre otros factores.

Rojas (2008) expresa que "la selección de una universidad y de una carrera es un tema bastante complejo para el joven, pues existen múltiples variantes del problema de la 
orientación vocacional, que es bastante precaria" (p.8). En este sentido, conviene afirmar que en Latinoamérica, la juventud se ve expuesta a la selección inadecuada de carreras universitarias que distan mucho de sus habilidades personales. Frecuentemente, los estudiantes suelen darse cuenta de que la escogencia del estudio de una determinada profesión fue errada y optan por abandonarla en la mitad o al final de la misma, sin obtener un título académico. Podría señalarse que la falta de autoconocimiento propicia que los jóvenes asuman planes inconsecuentes con sus verdaderas potencialidades que, a futuro, terminan en frustración.

Estos aspectos de índole personal e institucional contribuyen a que el individuo se ausente del aula de clases al no poder cumplir con sus obligaciones académicas, lo cual influye en su motivación o percepción que tenga del proceso de enseñanza y aprendizaje. Adicionalmente, a estos factores dilucidados, anteriormente, en la actualidad los estudiantes universitarios se muestran más desafiantes ante el estatismo en que las universidades han caído. Por un lado, rechazan las viejas formas de enseñanza centradas en la acumulación de saberes teóricos sin una aplicación a la realidad circundante y por el otro, manifiestan cambios o transformaciones de parte de las academias, en las que se refleje la atención a sus necesidades e intereses.

Vélez y López (2004) al elaborar un estudio sobre la deserción en la Universidad de La Sabana, Colombia, encontraron que existe un subgrupo de estudiantes al que denominaron desertores transitorios que se retiraron de sus carreras con la finalidad de hacer una pausa temporal, debido a dificultades socioeconómicas. Por lo tanto, existen momentos en los cuales los universitarios pueden tomar la decisión de abandonar sus estudios, de manera temporal, en tanto sus recursos económicos puedan mejorar y permitirles continuar estudiando. Dentro de este orden de ideas, Castaño, Gallón, Gómez y Vásquez (2008) establecen que existen tres tipos deserción a saber: interna (atribuida al alumno cuando cambia de curso o carrera), institucional (abandono de la universidad y deserción del sistema educativo (abandono total de los estudios universitarios). Estas aseveraciones suponen que la deserción puede ser transitoria o permanente.

Mateus, Herrera, Perilla, Parra y Vera (2011) sostienen que las causas de la deserción se pueden abordar desde los enfoques: sociológicos (falta de integración de los estudiantes al entorno de la educación superior), económicos (incapacidad para solventar los costos de los estudios), organizacionales (carencia universitaria de servicios y beneficios de tipo social, sanitario y académico al estudiante), de interacciones (percepción de que los beneficios de continuar estudiando son bajos en comparación con otras actividades económicas que resultarían más rentables) y psicológicos (creencias, concepciones y conductas que influyen en la persistencia del individuo para continuar cursando una carrera). Al analizar estos enfoques se puede entender que la deserción es multifactorial y cada situación individual es particular.

Tinto (citado en Quíntela, 2013) indica que "la deserción no sólo depende de las intenciones individuales (agente a priori), sino también de los procesos sociales e intelectuales a través de los cuales las personas elaboran (en sentido psicológico) metas 
deseadas en una cierta universidad (interacción)" (p.86). En efecto, las posibilidades de logro del estudiantado, muchas veces, se ven supeditada a la influencia de elementos incontrolables, tales como encarecimiento de los costos académicos, lugar de residencia alejado del campus universitario, trabas en los procedimientos administrativos de la casa de estudios, entre otros.

Por su parte, (Abdala, Castiglioni \& Infante, 2008) abordan la deserción desde tres perspectivas, a saber: los factores decisionales por los que se eligió una carrera que resultan incoherentes con las capacidades y habilidades del estudiante; la deficiente formación del alumno que le impide afrontar de manera exitosa los estudios universitarios; la interacción entre docente-estudiante y las estrategias metodológicas utilizadas para la enseñanza que distan de la comprensión de las necesidades e intereses del alumnado; la pertinencia e identificación de los jóvenes con las instituciones académicas; y, por último, la falta de vinculación de la universidad con el estudiantado. Como se puede apreciar, las perspectivas que ofrecen estos autores subrayan la importancia de que las instituciones fomenten un acercamiento con los estudiantes y se estrechen lazos más sinceros que se traduzcan en el apoyo necesario para la prosecución.

Dentro de este orden de ideas, Olave, Cisneros y Rojas (2013) señalan que "tanto el abandono parcial o total de una carrera universitaria como el desempeño insuficiente en las distintas asignaturas se encuentran mediados por la lectura y la escritura" (.p. 468). La carencia de habilidades para la escritura académica podría circunscribirse dentro de los aspectos formativos del estudiantado, que tienden a provocar la deserción, como consecuencia de la imposibilidad de cumplir con las asignaciones de los profesores. Así, cuando se espera que el alumno desarrolle un texto de diversa índole, ajustado a las normativas institucionales, se observa inconstancia y posterior incapacidad para hacerlo, lo que va a terminar en una conducta de deserción universitaria. En cierto modo, el docente tiene responsabilidad en la poca implementación de estrategias que motiven hacia la superación de las barreras cognitivas que impiden escribir textos académicos con las condiciones mínimas de pensamiento crítico, exigidas para los estudios de tercer nivel.

Para Patiño y Cardona (2012) "la deserción recae en el estudiante y su familia que ven sus aspiraciones truncadas y con un sentido de frustración que genera inmovilidad social" (p.19). Así, el abandono de los estudios universitarios resulta ser un fracaso para el estudiante y para sus padres, dado que la consecución de metas académicas se ve imposibilitada ante la aparición de factores individuales, sociales, económicos e institucionales que van a repercutir, directamente, en una conducta de alejamiento del individuo del entorno académico. De este modo, un fracaso universitario va, posiblemente, a generar una situación de malestar en el individuo, quien continuará desertando de otros estudios superiores, debido a que se verá predispuesto a no seguir luchando por formarse intelectualmente.

\section{Factores que inciden en la deserción estudiantil}

Existen diversas circunstancias y situaciones que provocan que el individuo abandone lo 
estudios universitarios. Es indudable que un estudiante se enfrenta a un conjunto de factores que bien lo pueden impulsar a terminar una carrera o lo predisponen hacia el fracaso que se traduce en su retiro de la institución. Smulders (2018) señala que existen factores internos y externos que condicionan la permanencia del estudiante en la universidad. Los primeros se relacionan directamente con la situación económica del estudiante, mientras que los segundos son de tipo motivacional y vocacional de las carreras. Tomando en cuenta lo anterior, estos factores obedecen a la realidad individual y social del alumno en un contexto determinado.

En este sentido, a continuación se abordan varios factores que inciden en la deserción universitaria, considerando que, en algunos países la educación superior no es gratuita y, es el estudiante quien debe asumir la totalidad de los gastos.

\section{Factores individuales y motivacionales}

Cuando un joven o adulto toma la decisión de cursar una carrera universitaria, se basa en las posibilidades de obtener un empleo inmediato una vez obtenga el título profesional. Sin embargo, suele observarse que la carrera seleccionada está alejada de sus competencias y habilidades personales, lo cual le trae inconvenientes al cursar asignaturas o seminarios que le son difíciles y, termina reprobándolos. Hay estudiantes que exceden el tiempo reglamentario en la universidad debido a las dificultades que les supone entender los contenidos teóricos y prácticos de aquellos cursos obligatorios que deben tomar para cumplir con el proceso de formación teórica.

Gutiérrez y Méndez (2018) expresan que "el estudiante al ingresar a una institución de educación superior tiene, o debiera tener, la plena convicción de que esa profesión es la que cubrirá parte de su realización" (p.260). No obstante, la realidad contrasta con las verdaderas aspiraciones de los universitarios. Una consecuencia de estudiar aquello en lo cual no tienen las capacidades necesarias, es la existencia de profesionales frustrados e ineficientes. Un médico o docente frustrados van a ejercer su profesión de manera indebida, pues no tendrán la vocación de servicio ni la preparación indispensable para actuar convenientemente en su campo laboral.

El resultado es el cometimiento de errores procedimentales en el ejercicio profesional, dado que no tiene sentido de preocupación por realizar su trabajo de manera adecuada y se conforma con cumplir las funciones principales del cargo que ocupe sin tener una concepción innovadora e indagadora de la mejor forma de desempeñarse en su área. Un profesional frustrado es aquel que, a pesar de haberse graduado, con calificaciones dentro de una escala mediana, no tiene las competencias necesarias para actuar eficientemente como lo haría un profesional involucrado en mejorar con el tiempo y lograr convertirse en una referencia acertada en el campo laboral.

Un graduado de una carrera que posea poca capacidad para tomar decisiones acertadas, falta de emprendimiento e innovación y que se sujete la norma tradicional de no superar el trabajo mediocre que realizan muchos, es un ejemplo fehaciente de que no 
posee las cualidades necesarias para ejercer correctamente sus funciones. Gardner, Dussán y Montoya (2016) atribuyen como factor de deserción la falta de claridad en la elección de la carrera universitaria. Por ello, ocurre que muchos alumnos realizan un paseo académico a través diferentes carreras sin encontrar una meta que los conduzca a estudiar con vocación.

Si bien, el estudiante puede desarrollar sus habilidades en el transcurso de su formación, es pertinente que tenga el compromiso y disponibilidad para aprender aquellos aspectos teóricos o prácticos que no domina. La deserción provocada por este factor obliga al estudiante a retirarse, prácticamente en la mitad del período, en tanto los niveles de dificultad le impidan alcanzar las competencias técnicas y académicas requeridas para la consecución del título universitario.

Con frecuencia se escucha una frase alusiva a que los estudios universitarios no son para todas las personas. Se puede cursar una carrera por influencia familiar, por tratar de cumplir los sueños frustrados de los progenitores o por probar suerte en la universidad. Pero, a lo largo de los estudios, el individuo se da cuenta de que obtener una profesión no era lo que se proponía cuando egresó de la formación secundaria. Sin embargo, no es garantía de contar con profesionales altamente capacitados y comprometidos con el desarrollo del país.

El proyecto de vida constituye una oportunidad de trazarse objetivos personales que conduzcan a la formación de un ser humano más consciente de su propia realidad, y que, a la larga se convierta en un ente ser sensato y empático con los problemas de los demás. Asuaje y Araya (2009) señalan que:

El proyecto de vida constituye un elemento clave en el proceso educativo, puesto que indica un camino a seguir y fija unas potenciales metas alcanzables por el sujeto, las cuales agregan eficacia al proceso de enseñanza (...) otorga coherencia al devenir de las persona en diferentes momentos y marca su estilo de actuar, de relacionarse y de ver la vida (p.98).

Esta concepción evidencia que en la escuela, sumado a la formación intelectual del estudiante, tiene que buscarse la capacidad del individuo para obtener logros pertinentes con sus motivaciones y aspiraciones personales. Cuevas (2004) parte de la proposición individual de objetivos y metas que respondan a los propios intereses y a las potencialidades que se tienen para la obtención de resultados satisfactorios.

En vista de ello, cuando se desconoce el verdadero proyecto de vida, las decisiones que se toman, en la práctica suelen ser equivocadas, porque no están ajustadas a los objetivos o propósitos existenciales de la persona. Si un individuo se ha propuesto como proyecto la constitución de una familia sin obtener formación profesional, no debe juzgarse como una decisión desacertada. Al contrario está haciendo uso de su individualidad y de su criterio 
para seleccionar lo mejor para sí. Suele decirse que quien no estudia una profesión no es nadie en la vida, quizá porque la sociedad ha impuesto como norma valorativa alcanzar un máximo de conocimientos formales para ocupar cargos más influyentes en la estructura de un estado o nación.

A pesar de estas consideraciones, quien no tiene una carrera profesional se puede desempeñar adecuadamente en la sociedad, ejerciendo un oficio que no necesariamente sea indicativo de una mala educación. A veces las personas sin formación académica son más sabias que aquellas con títulos universitarios importantes, debido a que han aprendido a amar su oficio. Ramírez, Díaz y Salcedo (2017) señalan que las personas deben ser capaces de valorar sus objetivos de vida, lo cual no necesariamente se traduzca en cursar una carrera universitaria. Es así como no todos tienen las condiciones académicas para formarse en estudios de tercer nivel ni tienen entre sus prioridades obtener un título profesional.

\section{En este orden de ideas, Vega (2013) sostiene que}

La educación, como escenario de potenciación de proyectos de vida genera opciones formativas tendientes a atender la integralidad del sujeto, en tanto la complejidad de la naturaleza humana demanda iniciativas y elecciones que movilizan los procesos de personalización -individuación- y socialización de los sujetos, en función de todas las esferas de la formación y del desarrollo humano, personal, afectiva, lúdica, social, cultural, política. (p.81).

La educación ofrece alternativas para que el proyecto de vida atraviese el velo del mero desarrollo de actividades que no representen un aprendizaje significativo en el ser humano. Es así como invita a descubrir las verdaderas fortalezas, a encontrar y superar las propias limitaciones que impiden ver de manera objetiva y crítica la situación particular de cada individuo. Si en el proyecto de vida no se contempla obtener una educación de tercer nivel, no revela un desconocimiento de la realidad del sujeto. Al culminar la formación básica de carácter formal es posible que haya descubierto, por sí mismo, los planes personales y posiblemente la motivación que se tiene para el desarrollo de un oficio que no requiera certificación profesional.

El abandono de los estudios universitarios por razones atribuidas a no saber qué es lo que se quiere realmente hacer en la vida, es un comportamiento regular en los estudiantes, quienes pueden encontrar el rumbo en el transcurso de la carrera o, por el contrario, están más desorientados y toman la opción de retirarse. Se trata de lograr que aprenda a determinar objetivos y propósitos para que establezca un proyecto de vida acorde con sus necesidades, intereses y expectativas.

\section{Factores socioeconómicos}

Ante la falta de recursos económicos, quien cursa una carrera, tiene la opción de obtener un empleo de medio tiempo para cubrir sus gastos. Sin embargo, muchos universitarios se ven imposibilitados de aprobar el plan de estudios, debido a la 
interferencia del trabajo remunerado con el desarrollo de las actividades académicas, lo cual retrasa el período de culminación del proceso de formación teórica. También tiene la opción de postularse para una beca académica otorgada por la institución o por otro organismo gubernamental que le preste la ayuda necesaria para afrontar los gastos.

La crisis económica de los estudiantes es un factor que genera alejamiento y frustración, trayendo como consecuencia la poca prosecución en los estudios universitarios. La carencia de recursos, sumado a la insatisfacción de las propias necesidades individuales limita la obtención de título profesional es un tiempo adecuado. Villegas, Acosta y Cayaffa (2012) expresan que "la crisis que afecta a Venezuela no es transitoria, ni coyuntural, ni superable sólo con el alza de los precios del petróleo" (p.292). Con tal panorama es evidente que la influencia negativa de los problemas económicos causa en la percepción del alumnado actitudes de inconformidad y desmotivación por continuar cursando estudios universitarios, optando por dedicarse a otra labor que les resulte remunerativa o migran a otro país con mayores posibilidades de desarrollo personal.

Para Bravo, Illescas, Larriva y Peña (2017) estudiar una carrera y no terminarla representa una pérdida de dinero tanto para el estudiante como para el Estado que financia la educación superior. Al no terminar los estudios, una persona no recupera la inversión que realizó en la permanencia en la carrera o curso y una forma de hacerlo es a través de la obtención de un título universitario, mientras que la deserción ocasiona que los gastos realizados por el Estado en el mantenimiento de la planta profesoral y estructural de la universidad no se van compensados con el egreso de mayor cantidad de estudiantes que asuman labores profesionales en distintos ámbitos de un país.

También es procedente mencionar que la situación económica individual obliga al estudiante a obtener un empleo remunerado que interfiere con la asistencia a clases y limita sus potencialidades creadoras en el desarrollo de las actividades académicas, debido a la falta de tiempo y dedicación a las asignaciones. De acuerdo con Aguilera y Jiménez (2012) y Álvarez, Cabrera, González y Bethencourt (2006) las razones económicas inciden en el éxito que se tenga al cursar una carrera universitaria, bien sea en la continuidad de los aportes dinerarios de los familiares o en las ayudas económicas que dé la institución. Sin duda que formarse académicamente representa una erogación monetaria a sufragar de manera individual o mediante colaboraciones institucionales $y$, en tanto, se puedan costear es posible obtener una titulación en un corto o largo tiempo.

Es un hecho insoslayable la consecuente formación de profesionales que no ejercen sus carreras por falta de oportunidades en el mercado laboral. La situación radica en que los planes de estudio ofertados por las universidades son incoherentes con los planes de desarrollo de un país. Es entonces, cuando la inversión realizada en los estudios universitarios no se retribuye y, en el caso, de aquellas universidades públicas los gastos destinados a la formación no se ven recompensados con la contratación de profesionales útiles al Estado. 
Una oportunidad representa el cumplimiento de las metas planteadas por un individuo en un plazo específico. El caso de ejercer una carrera universitaria supone la obtención de un empleo acorde con los conocimientos y habilidades adquiridas a fin de recibir una remuneración satisfactoria que le permita vivir adecuadamente. Pero, la realidad de los países suramericanos contrasta con las expectativas de éxito de los profesionales, quienes se ven imposibilitados de poner en práctica su formación académica, debido a la escasez de trabajo. Álvarez y López (2011) expresan que "se han creado nuevas titulaciones y ha habido una apuesta decidida a favor de una formación práctica que capacite para el verdadero desempeño laboral" (p.44). Es muy cierto, que el mercado laboral está cambiando paulatinamente $\mathrm{y}$, hoy, las posibilidades de empleo se estrechan por el surgimiento de nuevas tecnologías que han sustituido la mano de obra. En este sentido, la competitividad se asienta como una característica necesaria para ser valorado por las capacidades que posea el aspirante a un empleo.

Cuando se es competitivo, se tiene la formación práctica requerida para el sostenimiento de un trabajo por un tiempo adecuado que le permita al empleado conseguir metas importantes dentro de la organización contratante. Gómez (2012) refiere que:

Las competencias de empleabilidad [son]... saberes y habilidades transversales, es decir necesarias en todo tipo de empleo, que se manifiestan en la capacidad de resolver problemas, particularmente en el ámbito laboral, aunque también pueden ser desarrolladas para enfrentar la vida cotidiana. (p.72).

Al no evidenciarse un grado de competitividad en un trabajador, los empleadores, por lo general, optan por contratar a otra persona más eficiente, que si bien va a cumplir las mismas funciones, pero lo hará con iniciativa y mayor nivel de productividad. Es pertinente preguntarse, ¿si las universidades han comprendido que se necesita formar a profesionales mucho más competitivos y capaces de asumir los riesgos del futuro?. La respuesta a esta interrogante subyace en la actualización de los planes de estudio acordes con las exigencias del mercado laboral. Hay universidades venezolanas que, a pesar de los cambios trascendentales en tecnología y desarrollo industrial, continúan formando a estudiantes con competencias básicas que solo representan un obstáculo y desfase en el mundo empresarial, como resultado de la falta de coherencia entre formación teórica y aplicación de tecnologías. Briceño (2014) sostiene que la educación superior requiere de una revisión de los procesos de docencia y gerencia institucional para incorporar en el sistema de enseñanza una lógica tecnológica con responsabilidad social, en aras de garantizar la creatividad e innovación. Por lo tanto, al fomentarse un modelo de enseñanza enfocado en la pertinencia social, económica y cultural se propiciará la formación de individuos más conscientes de sus propias realidades y capaces de aportar soluciones a los problemas de las comunidades en las cuales están insertos.

\section{Factores institucionales}

Muchos profesores universitarios, aún hoy, se encuentran sumidos en viejos patrones de enseñanza incoherentes con el dinamismo e innovación que presentan los estudiantes actuales y convierten el proceso de aprendizaje en un momento monótono y tedioso. Ante 
esta situación las clases resultan poco atrayentes y los alumnos prefieren no asistir, dado que muchas veces presencian largas ponencias, acompañadas de soliloquios que no generan curiosidad e interés en el público. Es conveniente que el docente trasmita una actitud de indagación y espíritu crítico en sus clases, que sea capaz de interpretar las necesidades de conocimiento $y$, a la vez, despierte entusiasmo por la búsqueda del saber. Cuando un profesor se erige como un típico catedrático que habla un lenguaje muy distinto al de sus estudiantes, no se produce una sintonía en el abordaje de un tema de estudio.

Hernández (2016) refiere que los roles del docente estriban en las exigencias sociales y pedagógicas que existen en un determinado contexto. Así, se puede tener un profesor motivador, empático e inspirador del aprendizaje. Si, por el contrario, se limita a una simple exposición de contenidos sin verificar lo poco o mucho que aprenden sus estudiantes, se convierte en un sujeto arrogante, cuyo principio de valoración del conocimiento es la complacencia que realice el estudiante del ego docente. Díaz, Rosero y Obando (2018) señalan que el profesor debe "retroalimentar: ofreciendo al evaluado la oportunidad de confirmar sus aciertos y clarificar sus errores siendo esta una de las funciones primordiales si se quiere realizar planes de mejoramiento y alcanzar aprendizajes significativos" (p.175). En efecto, el alumno requiere de una palabra de aliento e impulso hacia el logro de objetivos académicos, dando la posibilidad de mejorar sus habilidades y orientándolo hacia la excelencia.

Las presiones familiares y académicas pueden conducir a una valoración negativa de la universidad y pretender con ello aliviar la tensión mediante el retiro de la institución para conseguir sosegarse o regresar a un estilo de vida más tranquilo sin exigencias educativas.

Al sentirse desatendido el estudiante por parte del profesor, recurre a sus compañeros de clases para aclarar dudas o comprender aquellos contenidos que no logró entender con la explicación del educador. Pero, si no encuentra una orientación adecuada que le motive a buscar respuestas para sus preguntas, el universitario se va alejando progresivamente de los distintos cursos hasta producirse la deserción. Es importante brindar una atención a las diferencias individuales, a través de grupos de asesorías o tutorías que persigan la mejora de las competencias de los alumnos y se subsanen las deficiencias en cuanto a la falta de comprensión de los contenidos impartidos. Román (2013) manifiesta que un estudiante desertor puede considerarse como vencido por el sistema educativo superior cuando las prácticas docentes aplicadas no le permiten avanzar en sus estudios por la falta de apoyo académico.

Ferreyra y Rúa (2018) sostienen que "las prácticas de enseñanza, (...) son acciones conscientes, concretas, que se desarrollan en el contexto de las instituciones educativas y que implican situaciones de interacción con otras personas" (p.145). Si se genera una interacción bidireccional entre docente y alumno es posible lograr resultados favorables con relación a un aprendizaje significativo y la superación de obstáculos que aseguren la permanencia del universitario en la institución. 
Es conveniente que el profesor no adopte el sesgo, ni la predisposición al evaluar a los estudiantes, quienes al verse incomprendidos manifiestan sentimientos de minusvalía o menosprecio y toman la decisión de no seguir con sus estudios. Un docente centrado en la valoración de los aspectos externos sin contemplar las potencialidades auténticas de los educandos, promoverá la deserción sin darse cuenta. Silvera (2016) indica que un evaluador asume un papel autoritario, debido a las experiencias que haya tenido en su etapa como estudiante $y$, que repetirá en su rol de profesor. Es pertinente cambiar ese patrón de condenación al que se somete a los alumnos en las aulas de clases, quienes terminan pagando las culpas de una formación castradora que recibió su mentor y que, con el pasar del tiempo se hace más evidente en las prácticas de enseñanza que ejecuta en la universidad. Chiroleu (2011) expresa que la calidad de la educación también influye en los motivos para abandonar los estudios. Es muy cierto que en Latinoamérica la baja calidad de los cursos universitarios es una realidad que amenaza con influir en la permanencia de los estudiantes en las aulas y tiende a provocar incomodidad en el alumno, lo cual hace que valore la posibilidad de dedicarse a otras actividades no vinculadas con la formación profesional.

La función del docente no solo es transmitir conocimientos sino propiciar un clima de enseñanza favorable en el cual el estudiante se sienta identificado y comprendido para que así pueda lograr sus propósitos de formación universitaria. Tanto Esteve (citado en Gómez, Sánchez y Tovar, 2018) como Lacombe (2011) son partidarios de la necesidad de brindar apoyo y estímulo al alumno en el aula de clases con miras a fomentar la búsqueda de un aprendizaje que trascienda la simpleza de permanecer como un sujeto pasivo incomprendido por el docente. De esta manera, un profesor debe representar un guía que promueva el interés y participación de sus educandos para evitar la deserción.

La revisión teórica sugiere que el abandono de los estudios es una conducta común el ámbito universitario latinoamericano y su interpretación radica en el abordaje individual, social e institucional que se realice al estudiantado. Pretender enfocarse en una sola causa de deserción implicaría un reduccionismo de los factores internos y externos que subyacen en la investigación del fenómeno. Tampoco es posible abordar realidades socioeconómicas de otros países a la situación local de una nación. Es pertinente considerar los aspectos institucionales como una de las tantas causas para abandonar una carrera y estudiarla bajo el panorama de los demás factores externos al individuo y la universidad que inciden en la falta de persistencia de quienes optan por retirarse de la academia.

En Venezuela, la deserción estudiantil universitaria ha existido también en el siglo XX, sin embargo, las circunstancias socioeconómicas actuales ha acentuado el fenómeno incrementado los porcentajes a un nivel de más de la mitad de los inscritos. La falta de adecuación del sistema de educación superior ante las oportunidades del mercado laboral representa una causa de abandono de los estudios. Estudiar una profesión que no está en correspondencia con las vacantes o trabajos, con los cuales se cuenta, incide en la aparición de sentimientos de desmotivación y apatía. La economía venezolana ha marcado los criterios de selección de las carreras universitarias, en detrimento de desaprovechar las habilidades de los bachilleres. El estudio de una profesión con la cual no se sienta identificado y que, simplemente, obedezca a criterios utilitaristas tiende a repercutir en la 
generación de frustración en el estudiantado.

La universidad actual exige tener profesores actualizados que, en vez de continuar con una función meramente docente, constituyan ejemplos vivaces de logro y superación personal para que promuevan una motivación hacia la búsqueda o desarrollo de las habilidades de los educandos. Al ponerse en práctica este principal requerimiento formativo, se logrará aumentar el nivel de permanencia de los alumnos, quienes pueden atravesar momentos de precariedad, pero la motivación que se les ofrezca los impulsará a proseguir sus estudios y vencer las dificultades en las cuales se encuentren. Es importante eliminar aquellas actitudes de los docentes en las cuales se desmotive a los educandos, poniendo barreras psicológicas infranqueables que les haga huir de la universidad. Al contrario, se trata de lograr que los alumnos descubran su verdadera vocación profesional y comprendan sus propias habilidades para que las ejecuten en el aula de clases.

\section{Método}

Esta investigación se circunscribe dentro del paradigma cualitativo, dado que se parte del tratamiento de datos de una determinada realidad a través de la consulta de fuentes documentales, las cuales aportan información relevante para la interpretación de situaciones y actitudes insertas en la deserción estudiantil universitaria en el contexto venezolano. Asimismo, se orienta hacia el paradigma cuantitativo, ya que se analizan datos estadísticos, expresados por medio de porcentajes que establecen un comportamiento en el número de alumnos universitarios ausentes en diferentes momentos.

Sumado a lo anterior, la investigación utilizó el diseño emergente porque pretende generar conocimiento sobre una realidad socioeducativa existente en las universidades venezolanas, mediante el estudio de los elementos relacionados con la causas de la deserción, empleando la revisión y contrastación de fuentes hemerográficas, en las cuales se abordaba el problema. Para Hernández, Fernández y Baptista (2010) y Valles (1997) el diseño emergente le otorga libertad al investigador para acceder a los datos e interpretarlos de una manera reflexiva que permita la comprensión de las interacciones presentes en el fenómeno abordado, sin seguir una estructura rígida que le impida darse cuenta de la dimensiones de la realidad, objeto de indagación.

Así, se obtuvieron estadísticas de deserción y se sometieron a la comparación y contraste, verificando las coincidencias entre las fuentes consultadas. Posteriormente, se analizaron las posibles causas del fenómeno con atención en la realidad social venezolana y bajo un enfoque teórico que favoreciese la estimación de resultados y conclusiones pertinentes.

El tipo de investigación que se asumió es el descriptivo, pues se caracterizó el fenómeno de la deserción estudiantil en la Universidad de Los Andes. Según Perdomo (2005) los estudios descriptivos registran, analizan e interpretan realidades o procesos 
desde una visión del presente. En este sentido, la deserción es analizada a la luz de las circunstancias sociales y educativas que existen actualmente en la nación venezolana.

Tomando en cuenta la naturaleza y diseño de la investigación, los participantes y la muestra del estudio, estuvieron representados por unidades de análisis que, a su vez, se centraron en la revisión de fuentes documentales informativas que reportaban el nivel de deserción estudiantil en las principales universidades públicas del Estado venezolano. Las estadísticas obtenidas fueron comparadas y se tomaron como referentes, dado que para el momento de la investigación no se contaba con datos procesados por las universidades. Luego, se consideró la deserción en la Universidad de Los Andes, ubicada en el estado Mérida y que posee 11 facultades, distribuidas en el casco central la ciudad. En este caso, se procedió a la consulta de los reportes de ausentismo que se publicaron para dicha casa de estudios en fuentes periodísticas locales y nacionales.

Los participantes en el estudio estuvieron comprendidos por los avances estadísticos de deserción estudiantil revelados por la Universidad de Los Andes para último trimestre de 2017 e inicios de 2018, los cuales establecen determinadas cifras obtenidas mediante los reportes de ausentismo que suministran los docentes a cada facultad. Se consideró la deserción en las distintas facultades de la casa de estudios abordada, de acuerdo con el reporte general de estudiantes que han abandonado las carreras universitarias.

En cuanto a las técnicas empleadas, se realizó el análisis conceptual de los datos a través de la organización, clasificación y codificación de la información lograda por medios electrónicos. De acuerdo con Perdomo (2005) las técnicas de análisis están dirigidas a la interpretación de los resultados. Para ello se tomó en cuenta el objetivo de la investigación. En relación con los instrumentos, se procedió a la toma de notas en fichas de trabajo. Se consideró la ficha textual en la cual se recogieron las ideas fieles a los planteamientos de los autores consultados. De igual manera, se elaboraron fichas resúmenes y fichas mixtas que permitieron la incorporación de ideas propias del investigador en el desarrollo de la fundamentación teórica del artículo.

Una vez recopilados los datos estadísticos de deserción se procedió a su contrastación e interpretación para establecer cifras que permitiesen tener una apreciación general de dicha realidad en la Universidad de Los Andes, a la luz de los planteamientos teóricos establecidos por los estudiosos del problema.

\section{Resultados}

\section{Causas de la deserción estudiantil en la Universidad de los Andes}

No existen estadísticas oficiales emitidas por la ULA del porcentaje de deserción en los años 2017-2018 y aún se está procesando la información, debido a que los estudiantes que no asisten a clases, todavía se mantienen en la matrícula, pues no se formalizan sus retiros parciales o definitivos en las diferentes carreras. A pesar de esta limitación, se pueden señalar un conjunto de causas que han provocado este fenómeno. En razón de 
ello, a continuación se esbozan las posibles causas que han incidido en la deserción estudiantil en la casa de estudios, antes señalada.

\section{Aumento de los alquileres de habitación para estudiantes procedentes de otros} lugares

Es bien conocido que en la ULA se matriculan estudiantes procedentes de otras ciudades de Venezuela y, por ende, deben arrendar o alquilar habitaciones o casas que le sirvan para alojarse mientras cursan las carreras universitarias que seleccionaron. Para ello, se ubican en habitaciones de casas de alquiler o en apartamentos, cuya renta normalmente es cancelada por los padres de los jóvenes. Sin embargo, desde hace varios años, los alquileres aumentaron sustancialmente, haciendo imposible que un estudiante pueda cubrir dichos gastos (Blanco, 2017). Ante esta situación muchos universitarios han tenido que retirarse de sus estudios, pues no consiguen financiamiento que les pueda ayudar a costearse el alojamiento. Es conveniente destacar que la Universidad cuenta con un servicio de residencia estudiantil gratuito, pero la demanda de solicitantes supera la oferta y muchos universitarios se ven obligados a alojarse en habitaciones privadas, que con el pasar del tiempo y a medida que la inflación aumentaba, incrementaron sus rentas.

Al no poder alojarse aquellos estudiantes que provienen de lugares alejados al campus de la institución, toman la decisión de abandonar sus estudios tanto al inicio como a mitad de sus carreras académicas. Resulta lamentable que por razones de albergue los jóvenes vean truncadas sus metas de graduarse en una determinada profesión.

\section{Incremento de los costos de los libros, fotocopias y artículos de uso académico}

Estudiar una carrera profesional requiere que el estudiante adquiera determinados artículos para el cumplimiento de las actividades teórico-prácticas, sobre todos en aquellas carreras relacionadas con la ciencia y la tecnología. Cada vez es difícil costearse la compra de un libro, el fotocopiado de textos académicos, la impresión de trabajos escritos, la adquisición de equipos de laboratorio, materiales odontológicos, cuadernos o juegos geométricos, entre otros, los cuales son requeridos para distintas asignaturas (Fernández, 2016; Maldonado, 2017; y Yánez y Abreu, 2017). Ante el aumento de los precios de estos productos, los jóvenes optan por abandonar las asignaturas que les exigen tener materiales o equipos de uso indispensable.

De esta manera, las carreras como arquitectura, odontología, medicina, ingeniería, farmacia, bio-análisis y enfermería requieren que el estudiante adquiera materiales y utensilios que son necesarios para el desarrollo de competencias y habilidades de carácter instrumental. No se pueden sustituir el aprendizaje de saberes procedimentales si no se cuentan con los implementos adecuados. Es así como aquellos que no pueden costearse esos materiales terminan retirándose de las asignaturas. En este contexto, también es procedente señalar que los insumos médicos y farmacológicos dificultan el desarrollo de las prácticas estudiantiles y afecta la obtención de aprendizajes significativos para el alumno. 
Es preocupante observar que el costo de los libros aumenta, paulatinamente, aunado a la falta de papel que mantienen a algunas editoriales venezolanas en un estado de inactividad. La falta de libros es un factor grave que dificulta la formación en los estudiantes y los condena a la repetición de viejos conocimientos sin indicios de actualización.

\section{Problemas de transporte y pago de pasaje estudiantil}

En el estado Mérida se cuenta con un servicio de pago de pasaje estudiantil a través de una tarjeta prepagada a bajo costo, con la finalidad de que la población estudiantil pueda desplazarse a sus sitios de estudio sin que implique un elevado gasto, pues el gobierno central subsidia el costo. No obstante, los transportistas comenzaron a exigir a los estudiantes el pago de la mitad de pasaje, debido a que el subsidio del Estado es insuficiente y no lograba cubrir los gastos de reparación y mantenimiento de las unidades de transporte (León, 2017a). Por lo tanto, los jóvenes se vieron afectados, ya que no contaban con el dinero necesario para desplazarse a través de las diferentes rutas. Es procedente indicar que la ULA no cuenta con una ciudad universitaria donde se ubiquen las diferentes facultades y las mismas se encuentran dispersas en diferentes zonas de Mérida, lo cual motiva a desplazarse de un sitio a otro.

Sumado a ello, la inexistencia de unidades de transporte suficientes para cubrir la demanda estudiantil impide llegar a tiempo a las clases o cumplir con las actividades extra cátedra, lo que provoca el abandono de los estudios.

\section{Problemas de abastecimiento de alimentos}

Si bien el desabastecimiento de alimentos en el país es un problema que mantiene sumida a la población en la búsqueda continua de aquellos rubros indispensables para satisfacer las necesidades nutricionales diarias, tiene implicaciones en el contexto personal, familiar, laboral y social del individuo, dado que se requiere de tiempo para la adquisición de los productos escasos (Barreto, 2017). En el caso de los estudiantes, algunos son padres de familia y deben proveer a sus hogares de alimentos, lo cual interfiere con la asistencia a clases y la realización de actividades académicas, lo que, posteriormente, les afecta su permanencia en la universidad. A juicio de Albanes, Duque, López, Machado y Silva (citado en Nava, 2014), los venezolanos tienen una crisis alimentaria por causas inflacionarias, escasez e injerencia desmedida del gobierno en la producción.

El cumplimiento de las obligaciones familiares se ha convertido en una actividad difícil de lograr, a causa de que no se cuenta con un acceso adecuado a los productos alimenticios $y$, en muchas ocasiones, hay estudiantes que no asisten a clases para tener que proveerse de los insumos para su manutención. La ULA cuenta con servicio de comedor, pero este se ve limitado por el déficit presupuestario que impide satisfacer a la demanda estudiantil, ocasionando que los jóvenes deban incluir dentro de sus gastos la compra de comida en la calle. Desde este punto de vista, pareciese que los estudiantes ponen sus necesidades de alimentación por encima de sus metas académicas, al no poder comer, adecuadamente. Puede decirse que la prioridad es obtener comida y, los estudios 
representarían una actividad adicional que se realiza en función de que se haya proveído de alimentos.

\section{Protestas estudiantiles}

Las protestas estudiantiles siempre han sido una situación recurrente en la ULA desde hace varios años, pero desde 2014 han aumentado significativamente, dadas las críticas y desacuerdos del sector universitario con las políticas del gobierno venezolano actual. Son evidentes los actos de rechazo por parte de jóvenes estudiantes hacia el sistema de gobierno imperante. Al producirse manifestaciones y disturbios en las principales arterias viales de la ciudad de Mérida, se producen embotellamientos que dificulta la llegada al aula de clases (León, 2017a y 2017b). En otros casos, las actividades académicas son suspendidas debido a las situaciones de violencia, por tanto, muchos universitarios optan por ausentarse de la casa de estudios.

Entre los meses de abril-julio de 2017, se generaron diversas manifestaciones estudiantiles en las calles de la ciudad, en las cuales se obstaculizaban avenidas que conducían hacia las distintas facultades de la universidad, impidiendo el libre tránsito y acceso a profesores, estudiantes y demás personal de la institución. Ciertamente, la imposibilidad de llegar hasta los sitios de estudio, condujo a la disminución de la matrícula universitaria. En este sentido, la falta de garantías de libre tránsito, desarrollo de las clases en condiciones normales y paralización del transporte público provocó un ausentismo estudiantil que fue creciendo con el pasar del tiempo y, posteriormente, luego del receso docente, en septiembre de 2017, las aulas se mostraron más vacías.

\section{Asignación de cupos universitarios en carreras que no gozan de aceptación en los jóvenes}

La Oficina de Planificación del Sector Universitario (OPSU) es un ente gubernamental, encargado de la asignación de cupos universitarios a los jóvenes que deseen cursar una determinada carrera profesional, con base en el índice académico del bachiller. En los últimos años se han cambiado los estándares de asignación de cupos, dándosele significativa importancia al estrato de procedencia del aspirante. De este modo, quienes se ubican en estratos más humildes tienen la alternativa de ser asignados a carreras de gran demanda como medicina e ingeniería, a pesar de que posean bajo rendimiento. Quienes tienen preferencia por cierta carrera le son asignadas otras que no son de su interés (González, 2016).

Este procedimiento tiende a causar malestar en los estudiantes, por cuanto al ser ubicados en carreras profesionales que no despiertan su motivación, asisten a clases con bajo nivel de interés y participación, observándose casos de ausentismo. En algunas situaciones los estudiantes se retiran de la universidad e intentan ingresar a carreras que le agradan, pero, a veces fracasan en sus intentos y tardan varios años en lograr postularse. Así, se pueden entender que muchos universitarios tienen un amplio camino probando cuál es la carrera que le permitirá desarrollar sus habilidades y, por ende, se 
inscriben y reinscriben con la finalidad de poder comprobar su verdadera vocación y, por ello pierden tiempo.

Pocas competencias comunicativas y habilidades de reflexión y crítica en los estudiantes de pregrado

La educación venezolana está atravesando un momento difícil que incide en su calidad y prestigio. Los jóvenes, casi en su mayoría, tienen baja formación académica de bachillerato, puesto que no poseen competencias adecuadas para la lectura y la escritura, aunado a la poca capacidad lógico matemática, que les dificulta cursar con éxito las asignaturas. En muchos casos, los estudiantes de los primeros semestres tienen problemas para redactar, se expresan oralmente de forma inadecuada y tiene bajo dominio matemático. Esta situación les impide alcanzar logros significativos cuando cursan una carrera. En varias ocasiones, la frecuencia con que un estudiante repite una asignatura supera los años de escolaridad preestablecida en el pensum. Pimentel (2017) señala que los alumnos poseen una deficiente formación secundaria en las materias Química, Física y Matemática, ocasionándoles dificultades para cursar carreras de Ingeniería.

La culpa parece atribuírsele a la formación secundaria adquirida tanto en las escuelas públicas como privadas, dado que se hace poco énfasis en el desarrollo de la capacidad de análisis y síntesis, poco sentido crítico y falta de creatividad. Es innegable que en el sistema educativo venezolano la memorización parece dominar las competencias de los estudiantes, dificultando la comprensión de los contenidos en la universidad. Es ese momento cuando el joven comienza a comprobar que la formación primaria y secundaria no le ha permitido obtener conocimientos previos significativos y termina por desertar las carreras universitarias.

\section{Mercado laboral insuficiente para satisfacer las demandas profesionales}

Actualmente, en el país el mercado laboral se encuentra comprimido debido a la desaparición y migración de importantes empresas del sector industrial, manufacturero y de servicios como consecuencia de la restricción en el otorgamiento de divisas y expropiaciones gubernamentales. Este hecho ha traído como consecuencia la reducción de las ofertas de trabajo y que las universidades vean cómo algunas carreras no tienen pertinencia con la situación socioeconómica existente (Páez, 2017). En la ULA, hay carreras relacionadas con la educación, ingeniería, ciencias sociales y ciencias naturales que egresan a profesionales que se ven obligados a desempeñar otros oficios, pues en la nación no se cuenta con vacantes para la contratación de los mismos. Muchos estudiantes se dedican al trabajo informal para cubrir sus gastos (Pimentel, 2017). Este fenómeno genera insatisfacción en los profesionales y optan por migrar a otros países en espera de que puedan ser contratados y así ejerzan sus carreras. 
Creación de universidades paralelas con poca tradición de enseñanza y bajo nivel de calidad

Desde que se comenzaron a crear universidades paralelas a partir de 2006, por mandato presidencial, a objeto de aumentar la masividad en el subsistema educativo universitario, muchos bachilleres, recién egresados, optaron por estudiar en este tipo de instituciones, dado que el nivel de exigencia en el proceso de enseñanza y aprendizaje era bajo. Asimismo, los horarios, solían ser cómodos para aquellas personas que trabajaban. No obstante, los planes de formación de los profesionales distan del cumplimiento de un período de escolaridad inferior a los 4 años y la flexibilidad en los procesos de evaluación ha propiciado que egresen profesionales con poca cualificación.

Es así como quienes estudian en estas instituciones no cumplen con los requerimientos formativos necesarios para ejercer de manera idónea en el campo laboral, pues no poseen los conocimientos teóricos y prácticos que les permitan obtener un perfil personal y profesional acorde con las exigencias de contexto empresarial y académico (Vivas, 2011). Hay casos de estudiantes de la ULA que se retiraron y se inscribieron en la Universidad Bolivariana de Venezuela, una institución gubernamental paralela a las demás universidades públicas, que si bien aumenta la oferta académica, no tiene el prestigio ni la calidad educativa de las demás casas de estudios tradicionales.

\section{Comportamiento de la deserción estudiantil en la Universidad de Los Andes}

La medición de la deserción universitaria en la ULA es un procedimiento que no resulta exacto, pues muchos estudiantes a pesar de ausentarse de las aulas, no manifiestan su retiro de las asignaturas que cursan. Existen casos de alumnos que han migrado a otros países, pero aún permanecen activos en el sistema de la universidad e incluso llegan a acuerdos con los profesores para cursar las materias a distancia. También se presentan casos de deserción en aquellas asignaturas que exigen mayor compromiso y dedicación al estudio, más cursan aquellas que tienen la facilidad de entregar trabajos o asignaciones a distancia. Por ende, es difícil emitir cifras absolutas, pues esto implicaría la revisión de casos individuales a través de cada asignatura, semestre, carrera y facultad, lo cual requiere de tiempo y esfuerzo profesional en el levantamiento estadístico.

Sin embargo, tras la revisión de artículos publicados en medios digitales, en los que se entrevista a autoridades y funcionarios de la ULA, es posible señalar unas cifras aproximadas que resultan de la comparaciones entre las opiniones emitidas en fuentes periodísticas. No obstante, las cifras se consideran un esbozo a la realidad que se suscita en las aulas universitarias y proceden de la revisión de lo reportado por Capezzuti (2018), Dávila (2018), García (2018), Pérez (2018), Sánchez (2017) y Universidad de Los Andes (2016). No son datos concluyentes, puesto que existen variaciones en las informaciones encontradas en dichas fuentes, pero se reconoce que existe una realidad innegable y es que cada día la deserción aumenta en la institución, objeto de estudio. 
Gráfica 1: La deserción estudiantil de la ULA en el periodo 2015-2018

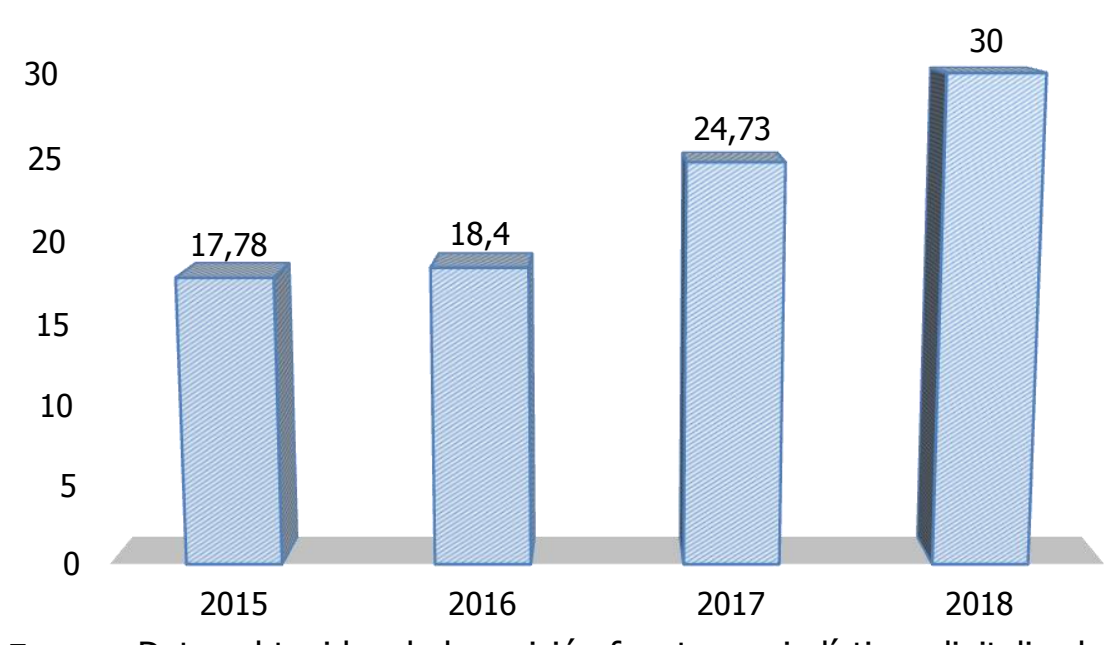

Fuente: Datos obtenidos de la revisión fuentes periodísticas digitalizadas.

Se puede observar que el comportamiento de la deserción estudiantil es de carácter creciente con incrementos significativos desde el año 2015, que pareciese estar íntimamente ligado con la desmejora de la situación socioeconómica del país. Para La Nación Web (2017) el porcentaje de estudiantes que ha abandonado las aulas de la institución a la que se hace referencia en este trabajo es de $65 \%$ entre los años 2015 y 2018, lo cual representa 25 mil universitarios. Esta cifra es altamente significativa, ya que representa un poco más de la mitad de los inscritos en la ULA, lo que es motivo de preocupación, pues evidencia un abandono importante de las aulas.

La situación analizada sugiere un incremento paulatino a través de los años y el agravamiento de la crisis económica venezolana. Según El Impulso (2018) y Prieto (2018) los estudiantes han puesto como prioridad la satisfacción de sus necesidades alimenticias, por encima de sus necesidades de formación universitaria. En muchas circunstancias los universitarios deben trabajar para poder mantener a sus padres y familiares, lo que los obliga a desertar de la universidad.

Con base en las causas de deserción antes descritas, se presenta una tabla que ilustra los factores que han propiciado el abandono de los estudios en la ULA.

Tabla 1: Factores y causas de la deserción estudiantil en la ULA-Venezuela

\begin{tabular}{ll}
\hline Factores de deserción & Causas de deserción \\
\hline Factores individuales & Bajos recursos económicos, escasez de insumos para cumplir \\
& con asignaciones académicas, poco apoyo familiar, problemas \\
de salud, necesidad de trabajar para la manutención de & padres y familiares, elección de carrera equivocada, deficiente \\
Factores sociales & formación secundaria del estudiante. \\
& Desmotivación del estudiante por crisis socioeconómica,
\end{tabular}


Factores institucionales

Factores motivacionales conflictos y enfrentamientos constantes entre sectores políticos y ciudadanos, falta de transporte, aumento del costo de vida de la población, alquileres elevados de pisos o habitaciones en las áreas urbanas cercanas a la universidad, desaparición de puestos de trabajo.

Carreras con pocas plazas en el mercado laboral, métodos de enseñanza desfasados con la realidad tecnológica y educativa actual del país, falta de atención a la realidad individual del estudiante, rigidez en la evaluación del alumno, pérdida de clases, ausentismo profesoral, alargamiento de los períodos lectivos, huelgas o paros de empleados y profesores.

Falta de vocación, depresión, desesperanza, poca valoración de los estudios universitarios en el país, estrés, presión social a favor de la migración.

Fuente: Elaboración propia

Al observar este cuadro que muestra los factores y las causas de deserción en la ULA, es posible entender el carácter multifactorial del fenómeno. No obstante, en la mayoría de las declaraciones de las autoridades universitarias el agravamiento de la crisis social, política y económica se incluye como una causa preponderante del abandono de las aulas universitaria. La falta de motivación debido a la exposición de los estudiantes a situaciones de conflicto y problemas de índole social repercute en su vocación o predisposición por elegir retirarse de los estudios. En Venezuela se está viviendo un hecho inédito como lo es la migración que subyace en el subconsciente individual y amenaza con convertirse en un comportamiento cotidiano en la población. Quintero (2016) sostiene que el entorno institucional y social tiene una marcada influencia en las decisiones de abandono de los estudios. Al extrapolar esta afirmación a la situación venezolana, se interpreta que los factores socioeconómicos han repercutido en la baja de la matrícula universitaria.

Es muy común observar en los estudiantes la priorización del entorno familiar sobre el educativo, como resultado del bajo poder adquisitivo que limita y coarta las aspiraciones formativas de los jóvenes. Canales (2007) expresa que la aparición de necesidades familiares que implican la manutención de padres o hijos, repercute en la deserción definitiva del estudiante. En efecto, los universitarios venezolanos se caracterizan por presentar realidades individuales distintas a las de finales de la década del siglo XX. Mientras que en aquellos tiempos un estudiante gozaba del privilegio de que sus padres le financiaran sus gastos universitarios, la situación actual les ha obligado a trabajar y estudiar, lo que a veces, incide en el cumplimiento de las actividades académicas.

\section{Discusión}

Las causas señaladas reflejan la fragilidad del sistema educativo universitario al no contar con políticas de apoyo y atención al estudiantado que experimenta momentos difíciles en el desarrollo de su formación académica. La falta de ayudas socioeconómicas, la carencia de programas que permitan reorientar a los alumnos para la superación de situaciones que tiende a tomar la decisión de desertar, obligan a las universidades venezolanas a repensar en las posibilidades de ofrecer motivación a aquellos estudiantes que experimentan conflictos emocionales. Al mismo tiempo puede señalarse que la existencia de profesores anclados en las viejas prácticas educativas que parecen invalidar los sentimientos de los alumnos, es un factor que atenta contra las expectativas de 
quienes cursan una carrera. La universidad es un espacio para el debate y la formación, pero también debe convertirse en un espacio de comprensión y diálogo que ayude al autoconocimiento. La deserción universitaria en Venezuela no debe suponer que es un fenómeno incipiente, sino que representa la exacerbación de una problemática que venía gestándose desde principios del milenio, y que, motivado a la ausencia de políticas de seguimiento y estímulo de la prosecución estudiantil, derivó en un incremento significativo de abandono.

Si se contrasta la realidad de la ULA con la teoría antes abordada, en materia de deserción estudiantil, es posible señalar la aparición de aspectos multifactoriales que han ocasionado el abandono de las carreras en un porcentaje que va más allá de la mitad de la matrícula inscrita. Uno de los referentes que puede permitir el análisis de la situación, anteriormente descrita, son los planteamientos de Mateus, Herrera, Perilla, Parra y Vera (2011), puesto que presentan distintos enfoques a los cuales se adscriben las causas esbozadas en el caso de la universidad, objeto de estudio en esta investigación. La preponderancia de los factores socioeconómicos incrementó o representó el detonante para que los universitarios consideraran la decisión de retirarse.

El hundimiento de la economía venezolana agravó las circunstancias individuales que ya venían exhibiendo una problemática de apatía o desinterés de los estudiantes en cursar carreras poco prioritarias para el desarrollo de la nación. Esta concepción funcional de la educación superior insta a que se escojan carreras con una alta preferencia que no encuentran relación con la existencia de suficientes plazas en el mercado laboral. No obstante, parece que la realidad del país ha sumido en un marasmo la permanencia en los estudios superiores y ha obligado a la población juvenil a interrumpir, intempestivamente, la asistencia a las aulas de clases, en vista de la falta de motivación para el ejercicio de una profesión en condiciones adecuadas de remuneración laboral. Dentro de este análisis se comparte las ideas de Álvarez y López (2011) y Briceño (2014) que sostienen una cierta modificación curricular de las universidades hacia la creación de carreras relacionadas con la formación en nuevos campos laborales en los cuales se trate de suplir la demanda de profesionales, sobre todo el área tecnológica que tanto hace falta preparar en Venezuela, en aras de mejorar la calidad de los servicios de comunicación.

Desde esta perspectiva, se coincide con (Abdala, Castiglioni \& Infante, 2008) en que la precisión de las causas del abandono debe propiciar la vinculación de la universidad con las necesidades e intereses del estudiantado, puesto que es conveniente la promoción de mecanismos que ayuden en la reducción de la cantidad de alumnos desertores. Lo ocurrido en el caso de las universidades venezolanas, sumado a la estrechez presupuestaria limitadora del desarrollo de proyectos y programas de atención al estudiante, es que las academias continuaron suponiendo que los jóvenes ingresados en estos últimos años, tienen las mismas concepciones, creencias y actitudes que aquellos cursantes de estudios a finales del siglo XX. Por ende, es importante fomentar el acercamiento entre docentes, autoridades y estudiantes con miras a abordar la realidad de cada individuo y presentar propuestas que motiven al logro académico. 
Al contrastar este análisis con las afirmaciones de Patiño y Cardona (2012) se evidencia una preocupación en el entorno familiar del estudiante, cuando se produce la deserción y la posterior migración de jóvenes a otros países, en búsqueda de nuevas oportunidades laborales. Las casas de estudios están experimentando un fenómeno de abandono de sus principales carreras y se ven expuestas a un posible cierre técnico, dada la falta de matrícula. En muchos hogares, los miembros de menor edad han emigrado, quedando solo aquellas personas adultas que por motivos de apego familiar o miedo a emprender nuevos rumbos no se atreven a irse del país. Por ello, el truncamiento de las aspiraciones personales de los universitarios es una de las razones principales para la deserción. Sienten que permanecer en Venezuela, solo les consumirá sus mejores años de juventud y las posibilidades de éxito que puedan tener. No es recomendable criticar a quienes emigran, sin antes conocer las motivaciones individuales que les ha impulsado a no continuar con su proceso de formación académica. Más bien es pertinente establecer contactos con los mismos y proponerles una futura prosecución cuando las condiciones sociales y económicas de la nación hayan mejorado.

Al considerar la situación socioeconómica del país como factor que influye en la deserción estudiantil, las aseveraciones sostenidas por Álvarez, Cabrera, González y Bethencourt (2006); Bravo, Illescas, Larriva y Peña (2017) y González, Miquilena, Rebolledo y Vásquez (2018) ponen de manifiesto que la falta de recursos económicos ha obligado a los jóvenes universitarios a establecer prioridades en las cuales la formación académica pasa a un segundo plano, pues mientras no se aprovisione de alimentos, difícilmente se tendrá motivación para proseguir con los estudios. Como bien se abordó en las causas de deserción, no contar con dinero condiciona y limita al individuo y hace que en sus pensamientos solo esté presente la satisfacción de las necesidades primarias.

En cuanto a los factores institucionales, el profesor universitario puede convertirse en un elemento que también ocasiona el abandono de las aulas. Las afirmaciones de Ferreyra y Rúa (2018), Lacombe (2011), Román (2013) y Suárez y Díaz (2015) expresan la necesidad de que el docente se convierta en un ente motivador y retenedor del estudiante en la universidad, en vez de ser un elemento que lo aleje de sus metas profesionales. En muchos casos, la consideración del alumno como un sujeto pasivo y hasta carente de conocimientos previos, provoca que no haya una interacción satisfactoria entre el agente de enseñanza y el aprendiz. En la ULA algunos docentes tienen una concepción tradicionalista de la enseñanza enfocada en la memorización que no hace empatía con las necesidades de estímulo y motivación que requiere el estudiante para proseguir con su carrera.

Otros de los factores a los cuales se les atribuye la deserción es el continuo estudio de carreras que no corresponden con la vocación de los estudiantes. Es innegable que en ciertas carreras, un joven descubra que la profesión que estudia no se relaciona con sus habilidades y preferencias académicas. Al respecto, las ideas de Gardner, Dussán y Montoya (2016) y Gutiérrez y Méndez (2018) evidencian la conveniencia de que el estudiante elija una profesión sobre la cual esté motivado y esto le asegurará la permanencia y prosecución en la universidad hacia la obtención de un título académico que le satisfaga. En la ULA algunos estudiantes asumen carreras que no les motivan y la 
situación económica actual les ha planteado la necesidad de autoevaluarse y reconducir sus estudios hacia metas verdaderamente alcanzables, según los recursos económicos y habilidades personales que posean.

Finalmente, dentro de este análisis el proyecto de vida que tenga los jóvenes venezolanos está supeditado a la situación socioeconómica presente. Es evidente que los indicadores económicos del país han propiciado que se asuman retos que sobrepasan las fronteras y provoca la elección de metas que no tienen asidero en el contexto nacional existente. Asuaje y Araya (2009); Cuevas (2004); Ramírez, Díaz y Salcedo (2017) y Vega (2013) expresan la determinación de objetivos realizables con base en intereses de mejora de la calidad de vida que no se tiene en el país. Por ende, cuando un joven migra está buscando nuevos rumbos hacia horizontes que satisfagan la necesidad de trabajar y ganar de dinero para el logro de sus metas personales y académicas. Es difícil retener a un alumno que no ve futuro en el país cuando las circunstancias individuales y sociales le son adversas. Ante esto, lo fundamental como profesor es permitir que el estudiante se autoevalúe y vea sus propias posibilidades de logro, bien sea realizando un oficio o ejerciendo una determinada profesión en otra nación.

\section{Conclusión}

Vistas algunas de las causas de la deserción estudiantil en la ULA, resulta preocupante el aumento del número de jóvenes universitarios que se retiran de esta importante casa de estudios. A pesar de que aún se están procesando las estadísticas definitivas de deserción en esa universidad, la observación empírica permite suponer que cada día son menos los alumnos que acuden a las aulas. Si se considera el porcentaje de deserción total de $65 \%$, se puede inferir que la crisis social y económica ha afectado la motivación por los estudios de pregrado.

La similitud con otras universidades públicas del país conduce a afirmar que los estudiantes muestran dificultades en la prosecución académica, desde el punto de vista económico, afectivo y cognoscitivo que demandan que el Estado examine el fenómeno con mayor detenimiento y rigurosidad, para plantear propuestas que aseguren a los jóvenes la permanencia en las instituciones universitarias. Si la deserción mantiene un alto porcentaje, se verán consecuencias negativas para la formación de recurso humano capacitado para el desarrollo de la nación. Al no contar con personal plenamente formado, la nación mantendrá un bajo nivel de crecimiento y es posible que muchas universidades tenga que hacer el cierre de carreras.

La posible desaparición de universidades de reconocido prestigio nacional e internacional en Venezuela, acentuará la crisis, pues son en estas casas donde se forma el pensamiento crítico y los estudiantes se convierten en transformadores y portadores del saber en la sociedad. Por ende, la deserción estudiantil es un síntoma creciente de la situación social, política, educativa y económica que se vive en la actualidad que debe ser examinado con mayor detalle para evitar convertirse en una nación sin formación académica. 
Entre las propuestas que podrían reducir el creciente aumento de este fenómeno está el cambio de concepción con respecto a los estudiantes por parte de los docentes universitarios. No es posible seguir pensando en que es un sujeto receptáculo de conocimientos y pretender enseñar sin atenderles la problemática socio-afectiva que experimentan en los actuales momentos. Las clases deben fomentar un espacio de motivación o apoyo, que contribuya a desarrollarles el amor por los estudios, la capacidad de logro y la superación de obstáculos. Un alumno motivado está más dispuesto hacia el aprendizaje. Por el contario, la generación de climas de estrés en el aula, solo traerá complicaciones y fomentará sentimientos de apatía que se traducirán en abandono de los estudios.

El profesor no debe ser motivo de deserción sino más bien de inclusión, que promueva la permanencia y prosecución en la universidad. Es necesario establecer programas de apoyo psicológico para los estudiantes, en función de despertar una cultura más crítica hacia la sociedad venezolana, capaz de orientarles ante decisiones de abandono de sus carreras. Es más loable aquel docente que inspira confianza y capacidad de superación que aquel tradicionalista y castrador de las verdaderas potencialidades del educando.

No obstante, la formación académica de bachillerato de los estudiantes, pertenecientes a las nuevas generaciones, suele caracterizarse por presentar deficiencias en sus competencias comunicativas y habilidades para la crítica y la reflexión. Es común observar a alumnos con poco interés en el desarrollo de las clases, falta de participación, apatía desmedida, ausencia de compromiso, actitud conformista y poco esfuerzo en aprender. Estas actitudes generan tensión con el profesorado, pues se busca a un individuo que sea expresivo, dinámico y que aporte ideas en la construcción y transformación del conocimiento. Posiblemente, el deterioro de la educación venezolana en los niveles primarios y secundarios, debido a la contratación de docentes sin preparación ni vocación pedagógica haya incidido en una formación deficiente de los bachilleres.

De este modo, en las universidades venezolanas el estudiante con baja preparación académica se encuentra limitado en el desarrollo de las actividades y se muestra incapaz de continuar con sus estudios, a causa de sus dificultades individuales. En ocasiones, es posible que la pasividad que exhiben los universitarios sea el resultado de una formación secundaria centrada en la excesiva memorización de conceptos sin su respectiva aplicación. La falta de participación y aporte de ideas en una clase por parte del estudiante es un indicativo de haber recibido una educación desfasada de la realidad que no fomenta la adquisición de habilidades investigativas y capacidad de emprendimiento para poner en práctica los saberes adquiridos.

Para afrontar esta situación, es conveniente que la universidad se integre con mayor nivel de profundidad con la comunidad y la escuela, a fin de sistematizar experiencias y establecer directrices que ayuden a mejorar la formación académica que se espera tengan los estudiantes cuando ingresan a una casa de estudios superior. Aunado a ello, se debe retomar los cursos preuniversitarios en los cuales se aclaren las dudas o se resuelvan las falencias de los estudiantes, en cuanto a los conocimientos y competencias básicas 
requeridas para el análisis, síntesis y procesamiento de información. También es recomendable que la interacción entre el docente y el alumno sea bidireccional, a objeto de entender las necesidades de los educandos y, a la vez, potenciar aquellas habilidades personales con miras a fomentar la deconstrucción y transformación del conocimiento. Igualmente, es pertinente que en el transcurso de la carrera se siembren valores morales, éticos y profesionales para lograr la motivación constancia, compromiso y emprendimiento de los estudiantes, en aras de buscar egresar a un individuo más dinámico, participativo y corresponsable con el desarrollo del país.

\section{Referencias}

Abdala, S., Castiglione, A. \& Infante, L. (2008). La deserción universitaria, una asignatura pendiente para la gestión institucional. Cuadernos de la Facultad de Humanidades y Ciencias Sociales, (34), 173-191. Recuperado de: http://www.redalyc.org/articulo.oa?id=18519814012

Agencia EFE. (2017, 17 de Febrero). Encovi: 82\% de los hogares está en pobreza. El Nacional. Recuperado de: http://www.elnacional.com/noticias/crisishumanitaria/encovi-los-hogares-esta-pobreza_81460

Aguilera, M. \& Jiménez, V. (2012). Factores de deserción universitaria en el primer curso de las carreras de Trabajo Social y Lengua Inglesa en las Facultades de Humanidades y Ciencias de la Educación y de Lenguas Vivas de la Universidad Evangélica del Paraguay. Revista Institucional de Investigación en Ciencias Sociales, 8(2), 197-205. Recuperado de: http://scielo.iics.una.py/pdf/riics/v8n2/v8n2a04.pdf

Álvarez, P., Cabrera, I., González, M. \& Bethencourt, J. (2006). Causas del abandono y prolongación de los estudios universitarios. Paradigma, 2Х1). Recuperado de: http://www.scielo.org.ve/scielo.php?script=sci_arttext\&pid=S101122512006000100002

Álvarez, P. \& López, D. (2011). El absentismo en la enseñanza universitaria: un obstáculo para la participación y el trabajo autónomo del alumnado. Revista Bordón, 63(3), 4356.

Asuaje, A. \& Araya, V. (2009). El proyecto de vida y su relación con el rendimiento académico en estudiantes de Educación Básica. Educare, 13(2), pp. 95-11. Recuperado de http://revistas.upel.edu.ve/index.php/educare/article/view/233/143

Banco Mundial. (2017). Venezuela panorama general. Recuperado de: http://www.bancomundial.org/es/country/venezuela/overview\#1

Barreto, J. (2017, 17 de Octubre). Alertan que en Venezuela se intensifica el hambre. El Nacional. Recuperado de: Recuperado de: http://www.elnacional.com/noticias/sociedad/alertan-que-venezuela-intensificahambre_208128 
Blanco, L. (2013). La deserción estudiantil: ¿realmente es un problema social? Revista de Posgrado FACE-UC, 712 , pp. 289-309. Recuperado de http://servicio.bc.uc.edu.ve/educacion/arje/arj12/art17.pdf

Blanco, D. (2017, 1 de Frebrero). Vivienda: alcancías que se rompen la inflación. El Carabobeño. Recuperado de https://www.el-carabobeno.com/viviendas-alcanciasserompen-inflacion/

Bravo, F., Illescas, L., Larriva, S. \& Peña, M. (2017). Causas de Deserción en el Ingreso a la Universidad; un Estudio de Caso. Revista de la Facultad de Ciencias Químicas, (18), 48-59. Recuperado

de: https://publicaciones.ucuenca.edu.ec/ojs/index.php/quimica/article/view/1693

Briceño. J. (2014). Reflexiones sobre la educación superior en Venezuela. Forum Comunitario, 12(2), 101-104. Recuperado de http://www.redalyc.org/articulo.oa?id=375740255014

Canales, A. (2007). Factores explicativos de la deserción universitaria. Revista Calidad en la Educación (26), 173-201. Recuperado de https://calidadenlaeducacion.cl/index.php/rce/article/view/239/242

Capezzuti, D. (2018, 16 de Marzo). Aula Abierta: la crisis actual ha originado la diáspora y deserción de estudiantes y profesores. El Universal. Recuperado de: http://www.eluniversal.com/politica/2939/

Castaño, E., Gallón, S., Gómez, K. \& Vásquez, J. (2004). Deserción estudiantil universitaria: una aplicación de modelos de duración. Lecturas de economía, (60), 3965. Recuperado de: http://www.redalyc.org/articulo.oa?id=155217798002

Castaño, E., Gallón, S., Gómez, K. \& Vásquez, J. (2008). Análisis de los factores asociados a la deserción estudiantil en la Educación Superior: un estudio de caso. Revista de Educación, (345), 255-280. Recuperado de: http://www.revistaeducacion.mec.es/re345/re345_11.pdf

Centro Interuniversitario de Desarrollo. (2006). Repitencia y deserción universitaria en América Latina. Santiago de Chile: UNESCO-IESALC. Recuperado de: https://www.cinda.cl/download/libros/Repitencia\%20y\%20Deserci\%C3\%B3n\%20Univ ersitaria\%20en\%20Am\%C3\%A9rica\%20Latina.pdf

Chiroleu, A. (2011). La educación superior en América Latina: ¿problemas insolubles o recetas inadecuadas? $S P, \quad 16(3)$, 631-653. Recuperado de: http://www.scielo.br/pdf/aval/v16n3/v16n1a08.pdf

Cuevas, J. (2004). Autoestima y motivación en la formulación de proyectos de vida en los estudiantes de III etapa de educación básica en la Escuela "Agua Negra", municipio Jiménez, estado Lara. (Trabajo de grado no publicado). Universidad Pedagógica Experimental Libertador, Barquisimeto, Venezuela.

Dávila, R. (2018). Deserción en la universidad fue analizada en Consejo Universitario de la ULA. Prensaula. Recuperado de http://prensa.ula.ve/2018/02/19/deserci\%C3\%B3n- 
en-la-universidad-fue-analizada-en-consejo-universitario-de-la-ula

Díaz, C., Rosero, K. \& Obando, M. (2018). La evaluación como medio de aprendizaje. Educación y Humanismo, 20(34), 173-186. DOI: http://dx.doi.org/10.17081/eduhum.20.34.2863

El Impulso (2018, 19 de Septiembre) Voluntad Popular: La deserción universitaria es un atraso para el país. El Impulso. Recuperado de https://www.elimpulso.com/2018/09/19/voluntad-popular-la-desercion-universitariaes-un-atraso-para-el-pais-19sep/

Fernández, A. (2016, 27 de Enero). Estudiantes están afectados por costo de fotocopias. El Tiempo. Recuperado de: http://eltiempo.com.ve/locales/regionales/educacion/estudiantes-estan-afectados-porcosto-de-fotocopias/209094

Ferreyra, H. \& Rúa, A. (2018). Dimensiones involucradas en el estudio de las prácticas de enseñanza. Educación y Humanismo, 20(34), 140-155. DOI: http://dx.doi.org/10.17081/eduhum.20.34.2861

Franquis, B. (2017, 22 de Septiembre) Hasta 250 docentes por facultad dejan las aulas de la UCV. El Nacional. Recuperado de http://www.elnacional.com/noticias/educacion/hasta-docentes-por-facultad-dejan-las-aulasucv_204683

García, C. (2018, 5 de Abril). 12.000 estudiantes dejaron estudios en núcleos de la ULA en 2017-2018. El Nacional. Recuperado de: http://www.elnacional.com/noticias/sociedad/12000-estudiantes-dejaron-estudios-nucleos-ula-20172018_229628

Gardner, L., Dussán, C. \& Montoya, D. (2016). Aproximación causal al estudio de la deserción en la Universidad de Caldas. Periodo 2012-2014. Revista Colombiana de Educación, (70), 319-340. Recuperado de: http://www.scielo.org.co/pdf/rcde/n70/n70a15.pdf

Gómez, M. (2012). La noción de empleabilidad: una mirada desde la perspectiva de las organizaciones. Revista Katharsis, (3), 63-83.

Gómez, C., Sánchez, V. y Tovar, G. (2018). Factores endógenos causantes de la permanencia irregular: una lectura desde el actuar docente. Revista Educación y Humanismo, 20(35), 96-112. DOI: https://doi.org/10.17081/eduhum.20.35.3030

González, L., Uribe, D. y González, S. (2005). Estudio sobre la repitencia y deserción en la educación superior chilena. Santiago de Chile: UNESCO-IESALC. Recuperado de: http://www.alfaguia.org/alfaguia/files/1318975876Estudio\%20sobre\%20la\%20repiten cia\%20y\%20desercion\%20en\%20la\%20educacion\%20superior\%20chilena.pdf

González, A. (2016, 4 de Septiembre). La sobreviviente Universidad de Los Andes. Diario de Los Andes. Recuperado de http://diariodelosandes.com/index.php?r=site/noticiaprincipal\&id=5413 
González, M., Miquilena, L., Rebolledo, A. y Vásquez, H. (2018). Deserción Estudiantil en la Universidad del Zulia ¿Problema Coyuntural? Revista Venezolana de Gerencia (RVG), 23(1), 403-431. Recuperado de http://produccioncientificaluz.org/index.php/rvg/article/view/23923/24358

Gutiérrez, D. \& Méndez, A. (2018). Buenas prácticas desde la percepción de los estudiantes de la Licenciatura en Educación para el Medio Indígena. Revista Educación y Humanismo, 20(34), 258-270. DOI: https://doi.org/10.17081/eduhum.20.34.2869

Hernández, R., Fernández, C. \& Baptista, P. (2010). Metodología de la Investigación. 5a ed. México: McGraw Hill.

Hernández, G. (2016). Risas y sonrisas del profesorado. Percepciones de estudiantes de la Universidad Veracruzana. Revista Educación y Humanismo, 19(32), 53-66. DOI: http://dx.doi.org/10.17081/eduhum.19.32.2531

Hernández, J. (2017, 6 de Octubre). Deserción universitaria: Escuela de Educación de la UCV no llega a los mil estudiantes. Caraota Digital. Recuperado de http://www.caraotadigital.net/nacionales/desercion-universitaria-escuela-deeducacion-de-la-ucv-no-Ilega-a-los-mil-estudiantes/

Lacombe, F. (2011). Reflexión de la práctica pedagógica. Revista Educación y Humanismo, 13(21), 191-308.

La Nación Web (2017, 29 de Noviembre) Deserción estudiantil en la ULA superó el 65\% durante el año 2017. Recuperado de https://lanacionweb.com/nacional/desercionestudiantil-en-la-ula-supero-el-65-durante-el-ano-2017/

León, L. (2017a, 4 de Mayo). Estudiantes de la ULA protestaron frente a la Catedral de Mérida. El Nacional. Recuperado de: Recuperado de: http://www.elnacional.com/noticias/sociedad/estudiantes-ula-protestaron-frentecatedralmerida_180563

León, L. (2017b, 21 de Mayo). Estudiantes de la ULA protestaron en rechazo a la represión en Mérida. El Nacional. Recuperado de Recuperado de: http://www.elnacional.com/noticias/protestas/estudiantes-ula-protestaron-rechazorepresionmerida_183486

Lobo, G. (2017; 29 de Septiembre) Deserción estudiantil sigue en aumento en las universidades venezolanas. Prensa ULA. Recuperado de: http://www.prensa.ula.ve/2017/09/29/deserci\%C3\%B3n-estudiantil-sigue-enaumentoen-las-universidades-venezolanas

López, L. \& Beltrán, A. (2012). Causas de la deserción en estudiantes de educación superior: el caso de la licenciatura en Contaduría. Pistas Educativas, 100(32), 112-125. Recuperado de: http://pistaseducativas.itc.mx/wp-content/uploads/2013/01/10LOPEZ-PE-100-112-125.pdf

Luengo, T. (2017, 16 de Febrero). Deserción universitaria se incrementó en 35\% en el Zulia. 
http://www.eluniversal.com/noticias/venezuela/desercion-universitaria-incrementozulia_640126

Maldonado, A. (2017, 7 de Febrero). Por deterioro y falta de insumos protestaron estudiantes de odontología. Prensa ULA. Recuperado de http://prensa.ula.ve/2017/02/07/estudiantes-de-foula-cerraron-las-puertas-deledificiodel-rectorado

Mateus, M., Herrera, C., Perilla, C., Parra, G. \& Vera, A. (2011). Factores presentes en la deserción universitaria en la Facultad de Psicología de la Universidad de San Buenaventura, sede Bogotá en el período comprendido entre 1998-2009 [Revista en línea]. Psycologia, Avances de la disciplina, 5(1), 121-133. Recuperado de http://www.redalyc.org/pdf/2972/297224114011.pdf

Nava, Y. (2014). El sector alimentario venezolano en la actualidad. Urbe, 12(1), 52-62. Recuperado http://publicaciones.urbe.edu/index.php/cicag/article/viewArticle/2843/4531

de:

Observatorio de la Diáspora Venezolana. (2017). Primer Informe del Observatorio de la Diáspora Venezolana. Recuperado de: https://www.google.com/maps/d/viewer?mid=1RSugU8ppV7SyOQiankjB_OJXC9s\&hl= en_US\&ll=-69.7026042290876\%2C141.4910563262696\&z=13

Olave, G. Cisneros, E. \& Rojas, I. (2013). Deserción universitaria y alfabetización académica. Educación y Educadores, 16(3), 455-471. Recuperado de http://www.redalyc.org/articulo.oa?id=83429830004

Páez, C. (2017, 30 de Julio). FMI: Venezuela tiene y mantendrá en 2017 la pero economía de la región. El Carabobeño. Recuperado de: https://www.el-carabobeno.com/fmivenezuela-mantendra-2017-la-peor-economia-la-region/

Para, K. (2017, 13 de Agosto). El chavismo lleva al exilio a más de dos millones de venezolanos. El País. Recuperado de: https://elpais.com/internacional/2017/08/10/actualidad/1502379778_751102.amp.htm I

Patiño, L. \& Cardona, A. (2012). Revisión de algunos estudios sobre la deserción estudiantil universitaria en Colombia y Latinoamérica. Theoria, 21(1), 9-20. Recuperado de: http://www.redalyc.org/articulo.oa?id=90231580008

Perdomo, R. (2005). Metodología de la Investigación jurídica. Mérida, Venezuela: Universidad de Los Andes, Consejo de Publicaciones.

Pérez, M. (2018, 22 de Octubre). Cifras de deserción estudiantil, docente y de trabajadores conoció el CU. Prensaula. Recuperado de: http://www.prensa.ula.ve/2018/10/22/consejo-universitario-conoci\%C3\%B3-cifras-dedeserci\%C3\%B3n-estudiantil-docente-y-de-personal-ato 
Pimentel, O. (2017, 30 de Octubre). Baja la tasa de aprobados en Ingeniería por deficiente formación. El Nacional. Recuperado de: http://www.elnacional.com/noticias/sociedad/baja-tasa-aprobados-ingenieria-por-deficienteformacion_209753

Prieto, E. (2018, 8 de mayo). ONG Aula Abierta: Deserción estudiantil en universidades supera 40\%. Analítica. Recuperado de: https://www.analitica.com/economia/aulaabierta-desercion-estudiantil-en-las-universidades-del-pais-supera-el-40/

Quíntela, G. (2013). Deserción universitaria, una aproximación sociológica al proceso de toma de decisiones de los estudiantes. Sociedad hoy, (24), 83-106. Recuperado de: http://www.redalyc.org/articulo.oa?id=90231580008

Quintero, I. (2016). Análisis de las causas de la deserción universitaria. (Tesis de especialización). Universidad Nacional Abierta y a Distancia, Bogotá, Colombia. Recuperado de: https://repository.unad.edu.co/bitstream/10596/6253/1/23783211.pdf

Ramírez, T., Díaz, R. \& Salcedo, A. (2017). ¿Abandono o deserción estudiantil? Una necesaria discusión intelectual. Investigación y Postgrado, 32(1), pp. 63-74. Recuperado de:_http://revistas.upel.edu.ve/index.php/revinpost/article/view/6252/pdf

Rojas, M. (2008). La deserción estudiantil en la Universidad de Ibagué: la perspectiva de los desertores. Revista Virtual Universidad Católica del Norte, (25). Recuperado de http://redalyc.uaemex.mx/src/inicio/ArtPdfRed.jsp?iCve=194215513006

Román, M. (2013). Factores asociados al abandono y la deserción escolar en américa latina: una mirada en conjunto. Revista Iberoamericana sobre Calidad, Eficacia y Cambio en Educación, 11(2), 33-59. Recuperado de: http://www.redalyc.org/pdf/551/55127024002.pdf

Sánchez, N. (2017, 29 de Diciembre). En 65\% se incrementó en el 2017 deserción estudiantil en la ULA [Artículo en línea]. Analítica. Recuperado de https://www.analitica.com/actualidad/actualidad-nacional/en-65-se-incremento-en-el2017-desercion-estudiantil-en-la-ula/

Silvera, L. (2016). La evaluación y su incidencia en la deserción escolar: ¿Falla de un sistema, de las instituciones educativas, del docente o del estudiante? Revista $\begin{array}{lllll}\text { Educación } y \text { Humanismo, 18(31), } 313-325 . & \text { DOI: }\end{array}$ http://dx.doi.org/10.17081/eduhum.18.31.1381

Smulders, M. (2018). Factores que influyen en la deserción de los Estudiantes Universitarios. Academo, 5(2), 127-132. Recuperado de: http://revistacientifica.uamericana.edu.py/index.php/academo/article/view/283

Suárez, N. \& Díaz, L. (2015). Estrés académico, deserción y estrategias de retención de estudiantes en la educación superior. Revista de Salud Pública, 172), 300-313. DOI: http://dx.doi.org/10.15446/rsap.v17n2.52891

Universidad de Los Andes (2016). Cifras de deserción estudiantil y profesoral continúan aumentando. Recuperado de: http://web.ula.ve/secretaria/2016/11/29/cifras-de- 


\section{desercion-estudiantil-y-profesoral-continuan-aumentando/}

Valles, M. (1997). Técnicas cualitativas de investigación social. Reflexión metodológica y práctica profesional. Madrid: Editorial Síntesis, S.A.

Vega, H. (2013). Características que evidencian el impacto educativo y cultural, a causa del fenómeno del desplazamiento forzado en Cúcuta. Educación y Humanismo, 15(25), 73-93.

Vélez, A. \& López, D. (2004). Estrategias para vencer la deserción universitaria. Educación y Educadores, 7, 177-203. Recuperado de: http://www.alfaguia.org/alfaguia/files/1319735698estrategias\%20para\%20vencer\%20 la\%20desercion\%20universitaria\%202004.pdf

Villegas, E., Acosta, A. \& Cayaffa, R. (2012). Venezuela ante la crieis global. Revista de Ciencias Sociales (Ve), (2), 283-294. Recuperado de: http://www.redalyc.org/articulo.oa?id=28023310009

Vivas, J. (2011). UBV: El gran fracaso de la educación bolivariana. Recuperado de: https://www.aporrea.org/educacion/a127451.html

Yánez, Y. \& Abreu, J. (2017). El costo de útiles y uniformes escolares supera el millón de bolívares en un año. Recuperado de. http://www.analitica.com/economia/el-costo-deutiles-y-uniformes-escolares-superael-millon-de-bolivares-en-un-ano/ 